\title{
Anti-inflammatory effects of Perilla frutescens leaf extract on lipopolysaccharide-stimulated RAW264.7 cells
}

\author{
BEE-PIAO HUANG ${ }^{1}$, CHUN-HSIANG LIN ${ }^{2}$, YI-CHING CHEN ${ }^{2}$ and SHAO-HSUAN KAO ${ }^{2,3}$ \\ ${ }^{1}$ Department of Pathology, Tungs' Taichung MetroHarbor Hospital; ${ }^{2}$ Institute of Biochemistry and Biotechnology; \\ ${ }^{3}$ Clinical Laboratory, Chung Shan Medical University Hospital, Taichung, Taiwan, R.O.C.
}

Received October 25, 2013; Accepted March 28, 2014

DOI: $10.3892 / \mathrm{mmr} .2014 .2298$

\begin{abstract}
Perilla leaves are widely used in Chinese herbal medicine and in Japanese herbal agents used to treat respiratory diseases. This study aimed to investigate the anti-inflammatory effects and the underlying mechanisms of Perilla frutescens leaf extract (PLE). Murine macrophage RAW264.7 cells were used as a model. Cell viability and morphological changes were studied by the MTT assay and microscopy. mRNA expression of pro-inflammatory mediators was assessed by both semi-quantitative reverse transcription-polymerase chain reaction (RT-PCR) and quantitative (q) RT-PCR. Nitric oxide $(\mathrm{NO})$ and prostaglandin $\mathrm{E}_{2}\left(\mathrm{PGE}_{2}\right)$ production were analyzed by the Griess test and sandwich enzyme-linked immunosorbent assay (ELISA), respectively. The activation of kinase cascades was studied by immunoblotting. Our findings showed that PLE slightly affects cell viability, but alleviates LPS-induced activation of RAW264.7 cells. Furthermore, PLE significantly reduced the LPS-induced mRNA expression of the interleukin $(I L)-6, I L-8$, tumor necrosis factor- $\alpha(T N F-\alpha)$, cyclooxygenase-2 (COX-2) and inducible nitric oxide synthase $(i N O S)$, genes in a dose-dependent manner. In addition, $\mathrm{PLE}$ reduced $\mathrm{NO}$ production and $\mathrm{PGE}_{2}$ secretion induced by LPS. PLE also inhibited activation of mitogen-activated protein kinases (MAPKs), increased the cytosolic I $\kappa \mathrm{B} \alpha$ level, and reduced the level of nuclear factor $(\mathrm{NF})-\kappa \mathrm{B}$. Taken together, these findings indicate that PLE significantly decreases the mRNA expression and protein production of pro-inflammatory mediators, via the inhibition of extracellular-signal-regulated kinase (ERK)1/2, c-Jun N-terminal kinase (JNK), p38, as well as NF- $\kappa$ B signaling in RAW264.7 cells stimulated with LPS.
\end{abstract}

Correspondence to: Dr Shao-Hsuan Kao, Institute of Biochemistry and Biotechnology, Chung Shan Medical University, No. 110, Sec. 1, Jianguo N. Road, Taichung 402, Taiwan, R.O.C.

E-mail:kaosh@csmu.edu.tw

Key words: Perilla frutescens, pro-inflammatory mediators, macrophage, nuclear factor- $\kappa \mathrm{B}$

\section{Introduction}

The leaves of Perilla frutescens are commonly used as decorative elements in Asia, including China, Japan and Taiwan. Dried red Perilla leaves are also used as 'soyou' in Chinese herbal medicine and are components of 'saiboku-to', which is a Japanese herbal formula that is commonly used to treat asthma. Previous studies have reported that Perilla frutescens leaf extracts (PLE) display a range of biological activities, including inhibition of tumor necrosis factor (TNF)- $\alpha$ (1), suppression of $\operatorname{IgA}$ nephropathy (2), and anti-inflammatory and anti-allergic activity $(3,4)$. However, the mechanisms underlying the anti-inflammatory properties of PLE are not well understood.

Inflammation is a response of organisms to pathogens and chemical or mechanical injury. Inflammatory response and tissue damage are induced by inflammatory mediators generated through upregulation of a number of inducible genes, including inducible nitric oxide (iNOS), cyclooxygenase (COX)-2, interleukin (IL)- 6 and $I L-8$. Nitric oxide (NO) is a messenger molecule that has critical functions in vascular regulation, host immune defense, neuronal signal transduction, and other pathways (5-7). NO is produced from the conversion of L-arginine to L-citrulline by the nitric oxide synthase (NOS) in the presence of oxygen and NADPH (8). NOS is inducible in macrophages and hepatocytes, and is activated following infection (9). Therefore, inducible (i)NOS-derived NO is an ubiquitous mediator of a wide range of inflammatory conditions, and its expression level reflects the degree of inflammation, thus providing a measure of the inflammatory response $(10,11)$. COX-2 also participates in immune system modulation and is involved in pathophysiological events (12). COX-2 is not expressed or is slightly detectable in most tissues under normal conditions; high expression of COX-2 following induction by pro-inflammatory mediators such as bacterial lipopolysaccharide (LPS), is involved in the pathogenesis of sepsis and inflammation $(13,14)$. In addition, compounds interfering with both iNOS and COX-2 generally act as inhibitors of a transcription factor required for iNOS and COX-2 expression, nuclear factor (NF)- $\mathrm{BB}(15)$.

Macrophages play a crucial role in eliciting NF- $\kappa B-$ related cascades at the acute phase of the inflammatory response. LPS stimulation of mouse macrophages leads to increased phosphorylation and activation of mitogen-activated protein 
kinases (MAPKs), such as extracellular-signal-regulated kinase (ERK)1/2, and c-Jun N-terminal kinase (JNK) (16). Therefore, the development of specific drugs to inhibit the production of these inflammatory modulators may be effective in the treatment of inflammatory diseases. In the present study, we investigated the anti-inflammatory effects and the underlying mechanism of a P. frutescens leaf extract (PLE). Specifically, we studied the regulation of gene expression of iNOS, COX-2, and pro-inflammatory cytokines in RAW264.7 cells stimulated with LPS.

\section{Materials and methods}

Chemicals and reagents. Aprotinin, leupeptin, LPS, 3-(4,5-dimethylthiazol-2-yl)-2,5-diphenyl-tetrazolium bromide (MTT), penicillin, streptomycin and other chemicals used in this study were purchased from Sigma-Aldrich (St. Louis, MO, USA). Dulbecco's modified Eagle's medium (DMEM), fetal bovine serum (FBS) and supplements for cell culture were purchased from Gibco-BRL (Gaithersburg, MD, USA). Antibodies targeting phosphorylated Erk1/2 (p-Erk1/2), total Erk1/2 (t-Erk1/2), phosphorylated JNK (p-JNK), total JNK (t-JNK), phosphorylated p38 (p-p38), total p38 (t-p38), I $\mathrm{B} \alpha \alpha$ and $\mathrm{NF}-\kappa \mathrm{B}$ (p65 subunit) were purchased from Cell Signaling Technologies (Beverly, MA, USA). The antibody targeting the glyceraldehyde 3-phosphate dehydrogenase (GAPDH) was purchased from Sigma-Aldrich. HRP-conjugated secondary antibodies targeting mouse and rabbit IgGs were purchased from Abcam (Cambridge, UK). The murine macrophage RAW264.7 cell line was obtained from the American Type Culture Collection (ATCC; Rockville, MD, USA).

Preparation of $P$. frutescens leaf extract (PLE). Perilla frutescens plants were purchased from a certified herbal pharmacy (Chung-Yi Chinese Herbal Medicine Pharmacy, Taichung, Taiwan). After dehydration, $100 \mathrm{~g}$ of the leaves were homogenized, and the powder was passed through a mesh $(0.05 \mathrm{~mm})$. The filtered powder was resuspended into 1 liter of $100 \%$ methanol and stirred at room temperature for 24 h. Following filtration on a Whatman no. 1 filter paper, the solution was lyophilized. Stock solution $(20 \mathrm{mg} / \mathrm{ml})$ of the extract was prepared in dimethylsulfoxide, and stored at $-20^{\circ} \mathrm{C}$ until further use.

Cell cultures and treatment. The RAW264.7 cells were incubated in DMEM supplemented with $0.1 \%$ sodium bicarbonate, $2 \mathrm{mM}$ glutamine, penicillin $\mathrm{G}(100 \mathrm{U} / \mathrm{ml})$, streptomycin $(100 \mu \mathrm{g} / \mathrm{ml})$ and $10 \% \mathrm{FBS}$, and were maintained at $37^{\circ} \mathrm{C}$ in a humidified incubator containing $5 \% \mathrm{CO}_{2}$. Following pre-incubation with different concentrations of PLE for $4 \mathrm{~h}$, $1 \mu \mathrm{g} / \mathrm{ml}$ LPS was added and then incubated for $2 \mathrm{~h}$ (NO assay), $3 \mathrm{~h}$ (RT-PCR and qRT-PCR analysis), or $24 \mathrm{~h}$ (cell viability assay and cell morphology analyses).

Cell viability assay. Cell viability was determined by an assay based on the mitochondrial-dependent reduction of MTT to formazan. Briefly, $10 \mu \mathrm{l}$ of MTT solution ( $5 \mathrm{mg} / \mathrm{ml}$ in DMEM) were added to the cell supernatant and incubated for $4 \mathrm{~h}$ at $37^{\circ} \mathrm{C}$. After removal of the medium, 2-propanol was added to lyse the cells and to solubilize the formazan. The optical density of formazan was measured at $570 \mathrm{~nm}$ using a microplate reader (Benchmark; Bio-Rad Laboratories, Hercules, CA, USA). The optical density of formazan generated by untreated cells was used to determine the $100 \%$ viability.

RNA extraction, reverse transcription polymerase chain reaction (RT-PCR) and quantitative (q)RT-PCR. Total RNA was isolated from individual samples, according to the manufacturer's instructions, using the RNeasy kit (Qiagen, Valencia, CA, USA). The purified RNA was used as a template to generate cDNA using the RevertAid ${ }^{\mathrm{TM}}$ First Strand cDNA Synthesis kit (Fermentas Life Sciences, St. Leon-Rot, Germany). The primer sequences used for RT-PCR and qRT-PCR are listed in Table I. RT-PCR experiments were performed in triplicates for each sample. Amplifications were performed using the ABI PRISM 7700 sequence detection system (Applied Biosystems, Foster City, CA, USA). For mRNA quantification, the FastStart Universal SYBR-Green Master mix (Roche Applied Science, Mannheim, Germany) was used. The cycle threshold $(\mathrm{Ct})$ values were calculated using the $\Delta \Delta C T$ method, and relative expression values were expressed by normalizing to the expression of GAPDH. qRT-PCR experiments were performed in duplicates for each sample. The size of the PCR products was confirmed by agarose gel electrophoresis.

NO assay. The NO level in cell culture supernatants was determined using the Griess test. Briefly, cells were treated with 1,5 , or $15 \mu \mathrm{g} / \mathrm{ml}$ PLE for $1 \mathrm{~h}$, followed by incubation with $1 \mu \mathrm{g} / \mathrm{ml} \mathrm{LPS}$ for $24 \mathrm{~h}$. Nitrite in the culture supernatants was mixed with the same volume of Griess reagent [ $1 \%$ sulfanilamide and $0.1 \% \mathrm{~N}$-(1-naphthyl)ethylenediamine dihydrochloride in 5\% phosphoric acid]. Absorbance was measured at $540 \mathrm{~nm}$, and the nitrite concentration was determined using sodium nitrite $\left(\mathrm{NaNO}_{2}\right)$ as a standard (17).

Enzyme-linked immunosorbent assay (ELISA). To analyze the production of pro-inflammatory mediators, cells were seeded in 6-well plates at an initial density of $5 \times 10^{5}$ cells $/ \mathrm{ml}$, starved in serum-free medium for $16 \mathrm{~h}$, pre-incubated with different concentrations of PLE $(5,10$ and $20 \mu \mathrm{g} / \mathrm{ml})$ for $1 \mathrm{~h}$, then treated with $1 \mu \mathrm{g} / \mathrm{ml}$ LPS for $24 \mathrm{~h}$. The supernatants were collected, and the concentrations of IL-6, IL-8 and TNF- $\alpha$, as well as of prostaglandin $\mathrm{E}_{2}\left(\mathrm{PGE}_{2}\right)$ were determined using DuoSet ELISA kits and the Prostaglandin $\mathrm{E}_{2}$ Parameter Assay kit (R\&D Systems, Abingdon, UK) respectively, following the manufacturer's instructions.

Subcellular fractionation. Cells were washed with physiological saline and incubated with lysis buffer [10 mM HEPES, $\mathrm{pH}$ 7.6, containing $15 \mathrm{mM} \mathrm{KCl,} 2 \mathrm{mM} \mathrm{MgCl}_{2}, 0.1 \mathrm{mM}$ EDTA, $1 \mathrm{mM}$ dithiothreitol, $0.05 \% \mathrm{v} / \mathrm{v}$ IGEPAL ${ }^{\circledR}$ CA-630, $1 \mathrm{mM}$ phenylmethanesulfonyl fluoride (PMSF), $1 \mathrm{mM}$ sodium orthovanadate, $50 \mathrm{mM}$ sodium fluoride, $10 \mu \mathrm{g} / \mathrm{ml}$ leupeptin, and $10 \mu \mathrm{g} / \mathrm{ml}$ aprotinin] for $10 \mathrm{~min}$. Following centrifugation at 2,500 $\mathrm{x} \mathrm{g}$ for $10 \mathrm{~min}$ at $4^{\circ} \mathrm{C}$, the supernatant was transferred into a new Eppendorf tube, further centrifuged at 20,000 x g for $15 \mathrm{~min}$ at $4^{\circ} \mathrm{C}$, and the new supernatant was collected as the cytosolic fraction. The pellets containing the nuclei were washed with physiological saline, incubated with a nucleus 
Table I. Primer sequences used for reverse transcription polymerase chain reaction (RT-PCR) and quantitative (q)RT-PCR.

\begin{tabular}{lll}
\hline \multicolumn{1}{c}{ Rene name } & \multicolumn{1}{c}{ RT-PCR } & \multicolumn{1}{c}{ qRT-PCR } \\
\hline$I L-6$ & F: 5'-ATGAACTCCTTCTCCACAAGCGC-3' & F: 5'-GTAGTGAGGAACAAGCCAGAGC-3' \\
& R: 5'-GAAGAGCCCTCAGGCTGGACTG-3' & R: 5'-GGCATTTGTGGTTGGGTCA-3' \\
$I L-8$ & F: 5'-AGATATTGCACGGGAGAA-3' & F: 5'-CTCTTGGCAGCCTTCCTGATTT-3' \\
\multirow{2}{*}{ iNOS } & R: 5'-GAAATAAAGGAGAAACCA-3' & R: 5'-CGCAGTGTGGTCCACTCTCAAT-3' \\
& F: 5'-CTGAGGGCTCTGTTGAGGTC-3' & F: 5'-GGCAGCCTGTGAGACCTTTG-3' \\
COX2 & R: 5'-CCTTGTTCAGCTACGCCTTC-3' & R: 5'-GCATTGGAAGTGAAGCGTTTC-3' \\
& F: 5'-GGAGAGACTATCAAGATAGTGATC-3' & F: 5'-CAGAACCGCATTGCCTCTG-3' \\
$T N F-\alpha$ & R: 5'-ATGGTCAGTAGACCTTTACAGCTC-3' & R: 5'-TTGTAACTTCTGGTCCTCATGTCGA-3' \\
& F: 5'-GCGACGTGGAACTGGCAGAAG-3' & F: 5'-GACCCTCACACTCAGATCATCTTCT-3' \\
GAPDH & R: 5'-TCCATGCCGTTGGCCAGGAGG-3' & R: 5'-CCTCCACTTGGTGGTTGCT-3' \\
& F: 5'-ACCACAGTCCATGCCATCAC-3' & F: 5'-ATGCCTCCTGCACCACCA-3' \\
& R: 5'-TCCACCACCCTGTTGCTGTA-3' & R: 5'-CCATCACGCCACAGTTTCC-3'
\end{tabular}

$I L$, interleukin; iNOS, inducible nitric oxide; $C O X$-2, cyclooxygenase-2; TNF- $\alpha$, tumor necrosis factor- $\alpha$; GAPDH, glyceraldehyde 3-phosphate dehydrogenase; F, forward; R, reverse.

lysis buffer $\left(25 \mathrm{mM}\right.$ HEPES, pH 7.6, 0.1\% v/v IGEPAL ${ }^{\circledR}$ CA-630, 1 M KCl,0.1 mM EDTA, 1 mM PMSF, 1 mM sodium orthovanadate, $2 \mathrm{mM}$ sodium fluoride, $10 \mu \mathrm{g} / \mathrm{ml}$ leupeptin, and $10 \mu \mathrm{g} / \mathrm{ml}$ aprotinin), and then centrifuged at 10,000 x $\mathrm{g}$ for $15 \mathrm{~min}$ at $4^{\circ} \mathrm{C}$. The resulting supernatants were collected as the nuclear fraction.

Immunoblotting. Cells $\left(5 \times 10^{5}\right.$ cells $\left./ \mathrm{ml}\right)$ were harvested, washed twice with ice-cold phosphate-buffered saline (PBS), and lysed in lysis buffer (50 mM Tris-HCl, pH 7.5, $150 \mathrm{mM} \mathrm{NaCl,} \mathrm{1 \%} \mathrm{v/v}$ IGEPAL ${ }^{\circledR}$ CA-630, 1 mM PMSF, 1 mM sodium fluoride, and $10 \mu \mathrm{g} / \mathrm{ml}$ aprotinin and leupeptin). The cell lysates were centrifuged at $14,000 \mathrm{x}$ g for $10 \mathrm{~min}$ at $4^{\circ} \mathrm{C}$ to remove the debris. The supernatants were collected and crude protein concentrations were determined using the $\mathrm{BCA}^{\mathrm{TM}}$ protein assay kit (Pierce, Rockford, IL, USA). Crude proteins (30 $\mu \mathrm{g} /$ lane) were electrophoresed and transferred onto a nitrocellulose membrane (Millipore, Bedford, MA, USA). After blocking with 5\% w/v skimmed milk in PBS, the membrane was incubated for $2 \mathrm{~h}$ with a 1/1,000 dilution of the specific primary antibodies. Bound antibodies were detected using a 1/2,000 dilution of peroxidase-conjugated secondary antibodies (Abcam) and ECL chemiluminescence reagent (Millipore) as the substrate. Three independent experiments were performed, and results were quantified by densitometry.

Statistical analysis. Data were expressed as means \pm standard deviation (SD) of the mean from three independent experiments. Statistical comparisons were performed by a one-way analysis of variance (ANOVA), followed by a Duncan multiple comparison test. Differences were considered statistically significant at $\mathrm{P}<0.05$.

\section{Results}

Effects of PLE on viability of murine macrophage RAW264.7 cells. The cytotoxic effect of PLE on viability of RAW264.7

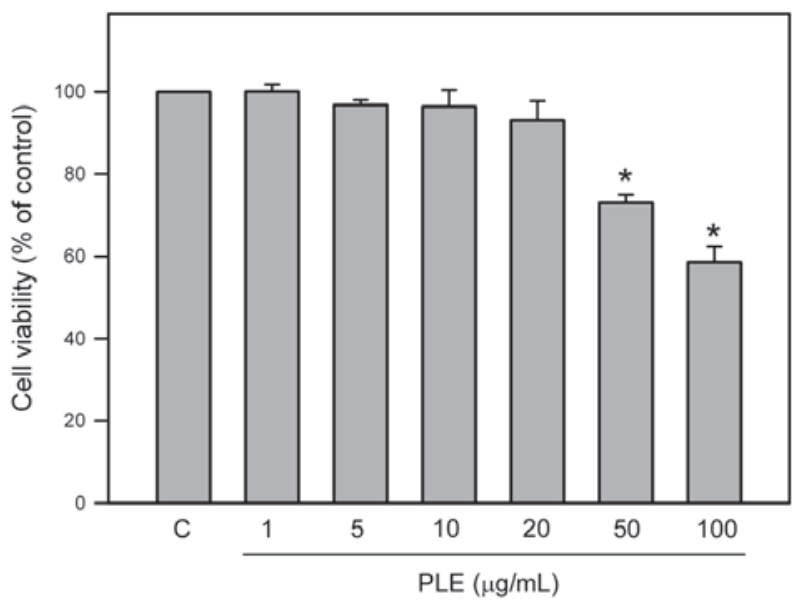

Figure 1. Effect of PLE on viability of RAW264.7 cells. Cells were incubated with different PLE concentrations $(1,5,10,20,50$ and $100 \mu \mathrm{g} / \mathrm{ml})$ for $24 \mathrm{~h}$, and the cell viability was determined by the MTT assay. ${ }^{*} \mathrm{P}<0.05$ as compared to the control (C; untreated cells). PLE, Perilla frutescens leaf extract.

cells was investigated by the MTT assay. As shown in Fig. 1, the viability of RAW264.7 cells was determined following incubation with different concentrations $(1,5,15,30,50$ and $100 \mu \mathrm{g} / \mathrm{ml}$ ) of PLE for $24 \mathrm{~h}$. The results revealed that treatment with concentrations of 50 and $100 \mu \mathrm{g} / \mathrm{ml}$ PLE significantly decreased the viability of RAW264.7 cells $(\mathrm{P}<0.05)$ compared to control (untreated) cells, while lower concentrations $(1,5,15$ and $30 \mu \mathrm{g} / \mathrm{ml}$ ) of PLE had no significant effect on viability of RAW264.7 cells.

PLE inhibits LPS-induced dendritic transformation of $R A W 264.7$ cells. LPS is known to induce morphological transformation of macrophage RAW264.7 cells (18). Therefore, whether PLE affects the LPS-induced morphological changes of RAW264.7 cells was investigated. As shown in Fig. 2, LPS alone significantly induced the morphological transformation of 

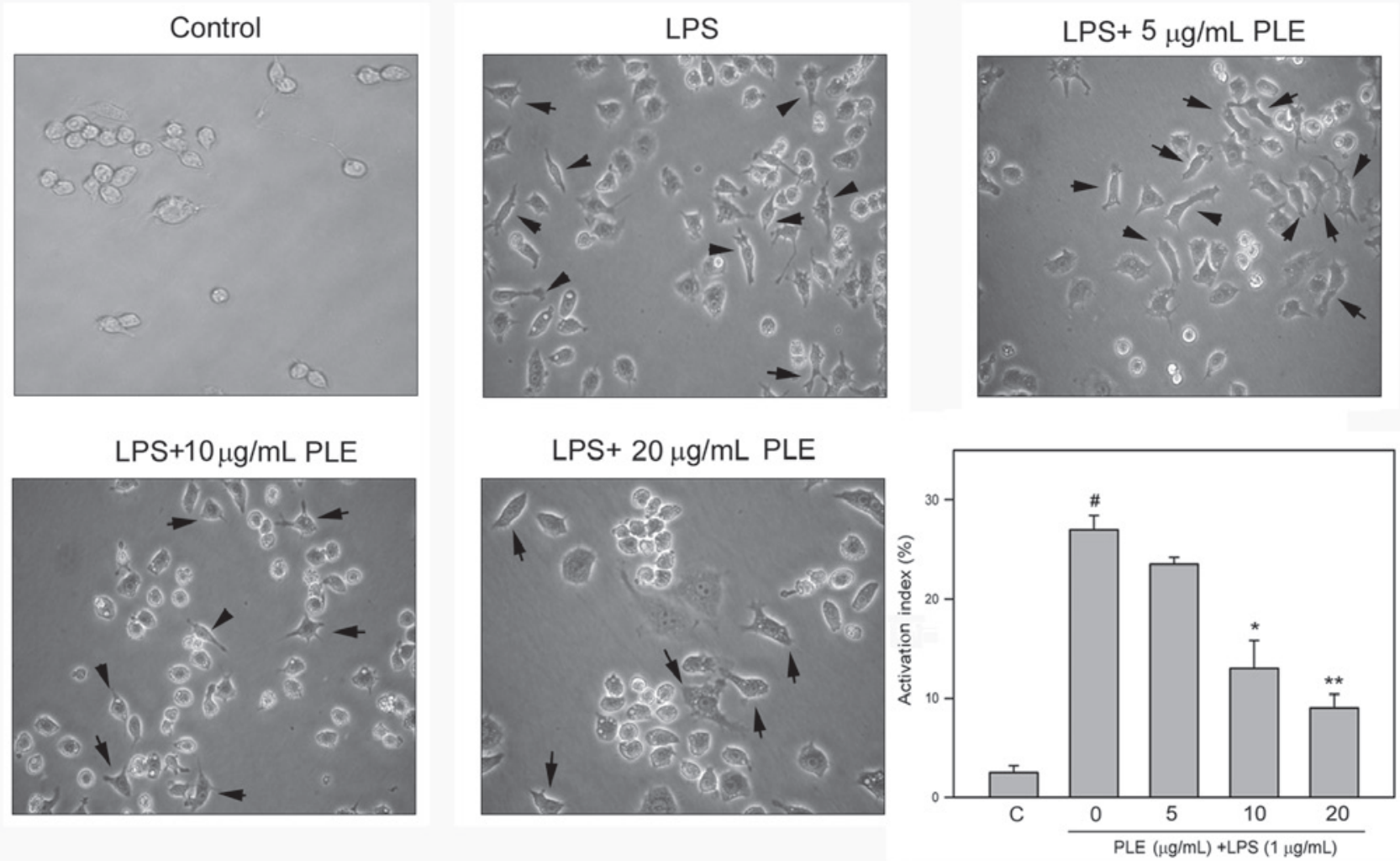

Figure 2. Effects of PLE on dendritic transformation of LPS-stimulated RAW264.7 cells. Cells were pre-incubated with the indicated concentrations of PLE in the DMEM culture medium for $4 \mathrm{~h}$, and then stimulated with $1 \mu \mathrm{g} / \mathrm{ml} \mathrm{LPS}$ for $24 \mathrm{~h}$. Cell morphology was monitored under a light microscope at $\mathrm{x} 400 \mathrm{mag}$ nitude. Activated RAW264.7 cells are indicated by arrows. The activation index percentage was expressed as the number of cells with activated morphology relative to the total number of cells, quantified in 5 random fields (number of total cells $>100$ ). ${ }^{*} \mathrm{P}<0.05$ as compared to the control (C; untreated cells); ${ }^{*} \mathrm{P}<0.05$ as compared to LPS alone. PLE, Perilla frutescens leaf extract; LPS, lipopolysaccharide.

RAW264.7 cells to dendritic cells, and this transformation was attenuated by PLE pretreatment in a dose-dependent manner. Further quantitative analysis revealed that LPS significantly increases the number of cells having a dendritic morphology to $27.0 \pm 0.5 \%$ ( $\mathrm{P}<0.05$ as compared to the control). When cells were pretreated with 10 or $15 \mu \mathrm{g} / \mathrm{ml}$ PLE and then treated with LPS, the number of cells with dendritic morphology was decreased to $13.6 \pm 1.6$ and $9.4 \pm 0.6 \%$, respectively ( $\mathrm{P}<0.05$ as compared to LPS treatment alone).

PLE inhibits LPS-induced $m R N A$ expression and production of IL-6, IL-8 and TNF- $\alpha$ in RAW264.7 cells. To investigate whether PLE affects the expression of pro-inflammatory cytokines in LPS-stimulated macrophages, the mRNA levels of $I L-6, I L-8$ and $T N F-\alpha$ were determined in LPS-treated RAW264.7 cells. RT-PCR analysis revealed that LPS alone enhances the expression of $I L-6, I L-8$ and $T N F-\alpha$, and this increase is reverted by pretreatment with PLE in a dose-dependent manner (Fig. 3A). Further quantitative analysis using qRT-PCR showed that treatment with LPS alone significantly increases the mRNA levels of $I L-6, I L-8$ and TNF- $\alpha, 3.9 \pm 0.4-, 13.8 \pm 1.5-$ and 5.4 \pm 0.3 -fold respectively (Fig. 3B), as compared to the control (untreated cells). In RAW264.7 cells pretreated with $20 \mu \mathrm{g} / \mathrm{ml}$ PLE and then treated with $1 \mu \mathrm{g} / \mathrm{ml}$ LPS, the mRNA levels of $I L-6, I L-8$ and $T N F$ - $\alpha$ were reduced $1.4 \pm 0.2-, 5.1 \pm 0.3$ - and 3.4 \pm 0.2 -fold as compared to the control, respectively $(\mathrm{P}<0.005$ as compared to LPS alone).
In addition to mRNA expression, LPS alone increased the protein production of IL-6, IL-8, and TNF- $\alpha$ in RAW264.7 cells (Fig. 3C) up to $135.7 \pm 18.9,145.9 \pm 21.3$ and $488.2 \pm 33.2 \mathrm{pg} / \mathrm{ml} / 10^{4}$ cells, respectively $(\mathrm{P}<0.05$ as compared to the control) . PLE pretreatment dose-dependently reduced the protein production of the tested cytokines (Fig. 3C) up to $59.3 \pm 5.6$ (IL-6), $38.2 \pm 3.9$ (IL-8) and $228.7 \pm 13.3 \mathrm{pg} / \mathrm{ml} / 10^{4}$ cells (TNF- $\alpha$ ), respectively $(\mathrm{P}<0.05$ as compared to LPS alone).

PLE inhibits LPS-induced mRNA expression of COX-2 and iNOS and the production of $P G E_{2}$ and NO in RAW264.7 cells. COX-2 and iNOS are both critical enzymes associated with macrophage-mediated development and progression of inflammation (19-21); therefore, effects of PLE on the mRNA level of COX-2 and $i N O S$ were analyzed and quantified in LPS-stimulated RAW264.7 cells. RT-PCR analysis showed that LPS treatment alone enhances the expression of $C O X-2$ and $i N O S$, and this increase was reverted by pretreatment with PLE in a dose-dependent manner (Fig. 4A). Further quantitative analysis using qRT-PCR revealed that LPS alone significantly increases the mRNA levels of $C O X-2$ and $i N O S$, 41.6 \pm 2.6 - and 24.9 \pm 4.3 -fold, respectively, as compared to the control $(\mathrm{P}<0.05)$. In RAW264.7 cells pretreated with $20 \mu \mathrm{g} / \mathrm{ml}$ PLE and then treated with $1 \mu \mathrm{g} / \mathrm{ml}$ LPS, the mRNA levels of COX-2 and $i N O S$ were dose-dependently reduced (Fig. 4B) $11.6 \pm 1.5$ - and $6.6 \pm 1.2$-fold as compared to the control, respectively ( $\mathrm{P}<0.05$ as compared to LPS alone). 


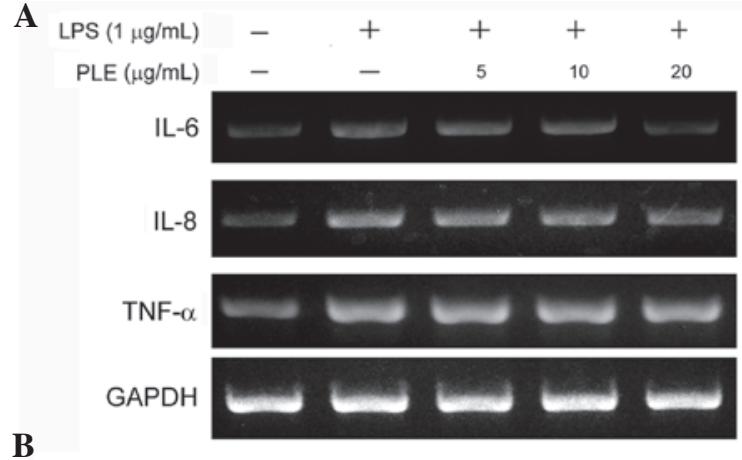

B

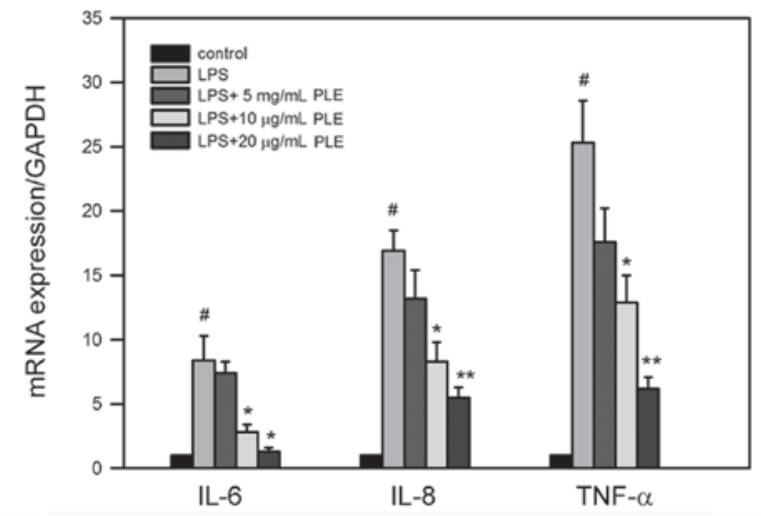

C

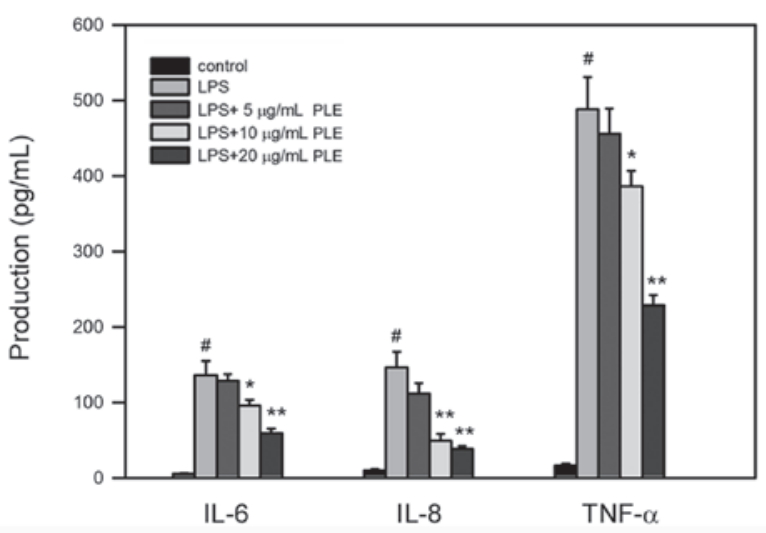

Figure 3. PLE reduces the mRNA level and the protein production of pro-inflammatory cytokines IL-6, IL-8 and TNF- $\alpha$ in LPS-stimulated RAW264.7 cells. Cells were pre-incubated with the indicated concentrations of PLE in the DMEM culture medium for $4 \mathrm{~h}$, and then stimulated with $1 \mu \mathrm{g} / \mathrm{ml}$ LPS for 6 or $24 \mathrm{~h}$. Following treatment, the cells were lysed for mRNA extraction, and the gene expression level was analyzed by (A) RT-PCR and quantified by (B) qRT-PCR, while the culture medium was collected to quantify the production of corresponding proteins by (C) ELISA. Bars denote standard deviation (SD) of the mean from three independent experiments. ${ }^{\#} \mathrm{P}<0.05$ as compared to the control (untreated cells); ${ }^{*} \mathrm{P}<0.05$ as compared to LPS alone. PLE, Perilla frutescens leaf extract; IL, interleukin; TNF- $\alpha$, tumor necrosis factor- $\alpha$; LPS, lipopolysaccharide; RT-PCR, reverse transcription-polymerase chain reaction; q, quantitative.

Since mRNA expression of COX-2 and iNOS in RAW264.7 cells treated with LPS was inhibited by PLE pretreatment, the production of $\mathrm{PGE}_{2}$ and $\mathrm{NO}$ was further assessed. As shown in Fig. 4C and D, treatment with LPS alone significantly increased the concentrations of $\mathrm{PGE}_{2}$ and $\mathrm{NO}$ up to $310.9 \pm 22.5 \mathrm{pg} / \mathrm{ml}$ and $25.3 \pm 1.6 \mu \mathrm{M}$, respectively. Upon pretreatment with 10 or $20 \mu \mathrm{g} / \mathrm{ml} \mathrm{PLE}$, the concentration of $\mathrm{PGE}_{2}$ was reduced down to $168.1 \pm 9.2 \mathrm{pg} / \mathrm{ml}$ and $118.7 \pm 3.1 \mathrm{pg} / \mathrm{ml}$, respectively, and the concentration of $\mathrm{NO}$ was decreased to $14.7 \pm 0.7$ and $5.5 \pm 1.3 \mu \mathrm{M}$, respectively ( $\mathrm{P}<0.05$ as compared to LPS alone).
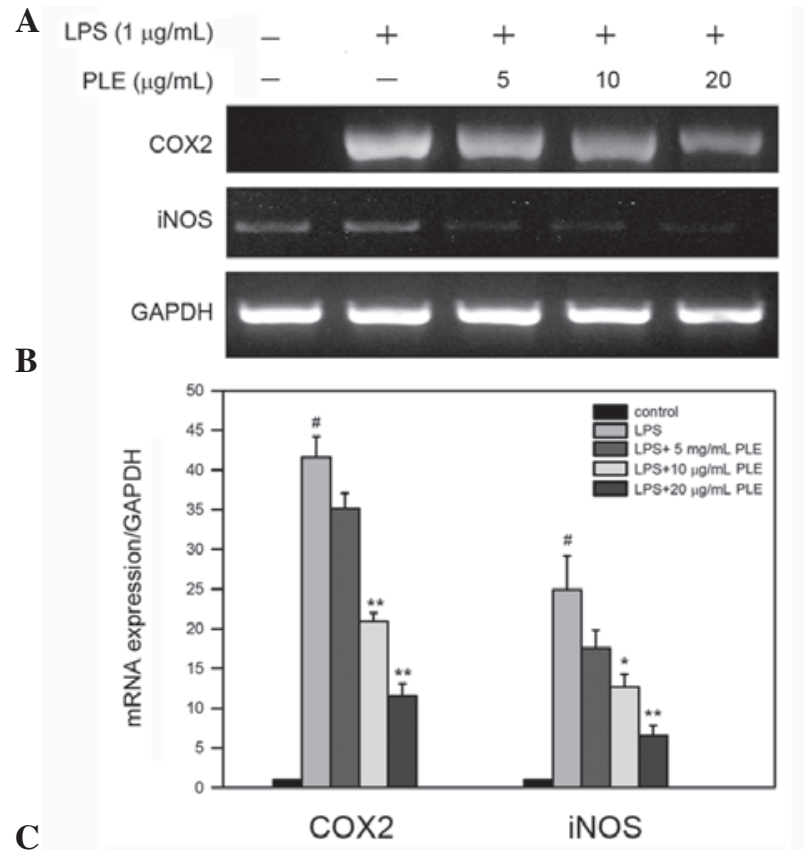

C

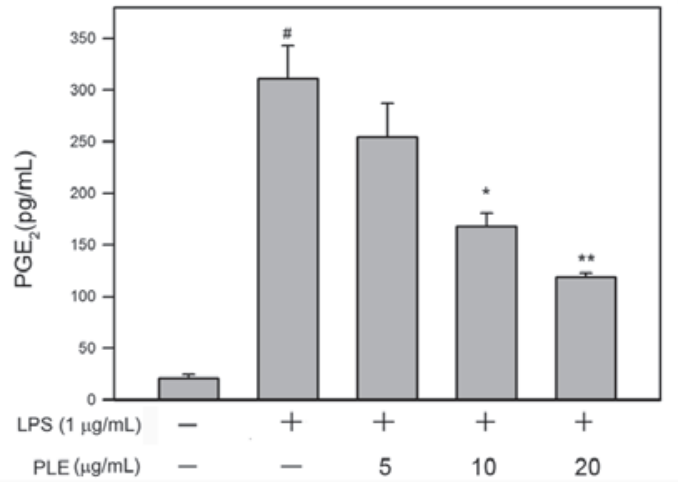

D

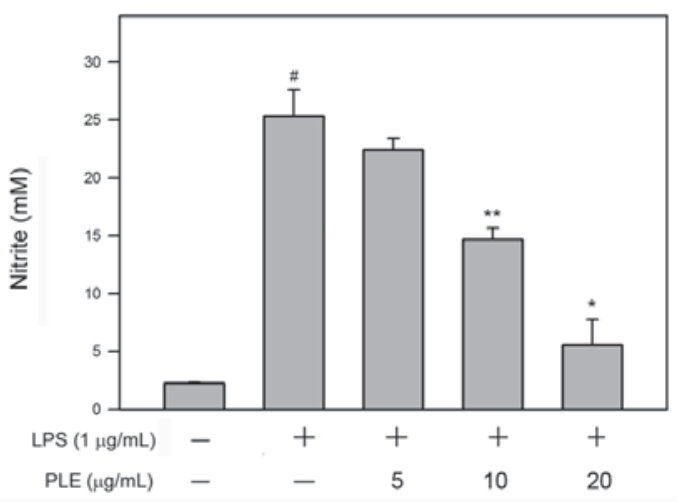

Figure 4. PLE reduces the mRNA level of $C O X-2$ and $i N O S$ and the production of PGE ${ }_{2}$ and NO in LPS-stimulated RAW264.7 cells. Cells were pre-incubated with the indicated concentrations of PLE in the DMEM culture medium for $4 \mathrm{~h}$, and were then stimulated with $1 \mu \mathrm{g} / \mathrm{ml}$ LPS for 6 or $24 \mathrm{~h}$. Following treatment, the cells were lysed for mRNA extraction and the expression level of COX-2 and $i N O S$ was analyzed by (A) RT-PCR and quantified by (B) qRT-PCR, while the culture medium was collected to quantify the production of (C and D) $\mathrm{PGE}_{2}$ and $\mathrm{NO}$ (nitrite). Bars denote standard deviation (SD) of the mean from three independent experiments. ${ }^{~} \mathrm{P}<0.05$ as compared to the control (untreated cells); ${ }^{*} \mathrm{P}<0.05$ as compared to LPS alone. PLE, Perilla frutescens leaf extract; LPS, lipopolysaccharide; $C O X-2$, cyclooxygenase-2; iNOS, inducible nitric oxide; $\mathrm{PGE}_{2}$, prostaglandin $\mathrm{E}_{2} ; \mathrm{NO}$, nitric oxide.

PLE inhibits phosphorylation of MAPKs, the degradation of $I \kappa B \alpha$ and the nuclear translocation of $N F-\kappa B$ in LPS-stimulated RAW264.7 cells. Activation of MAPKs 


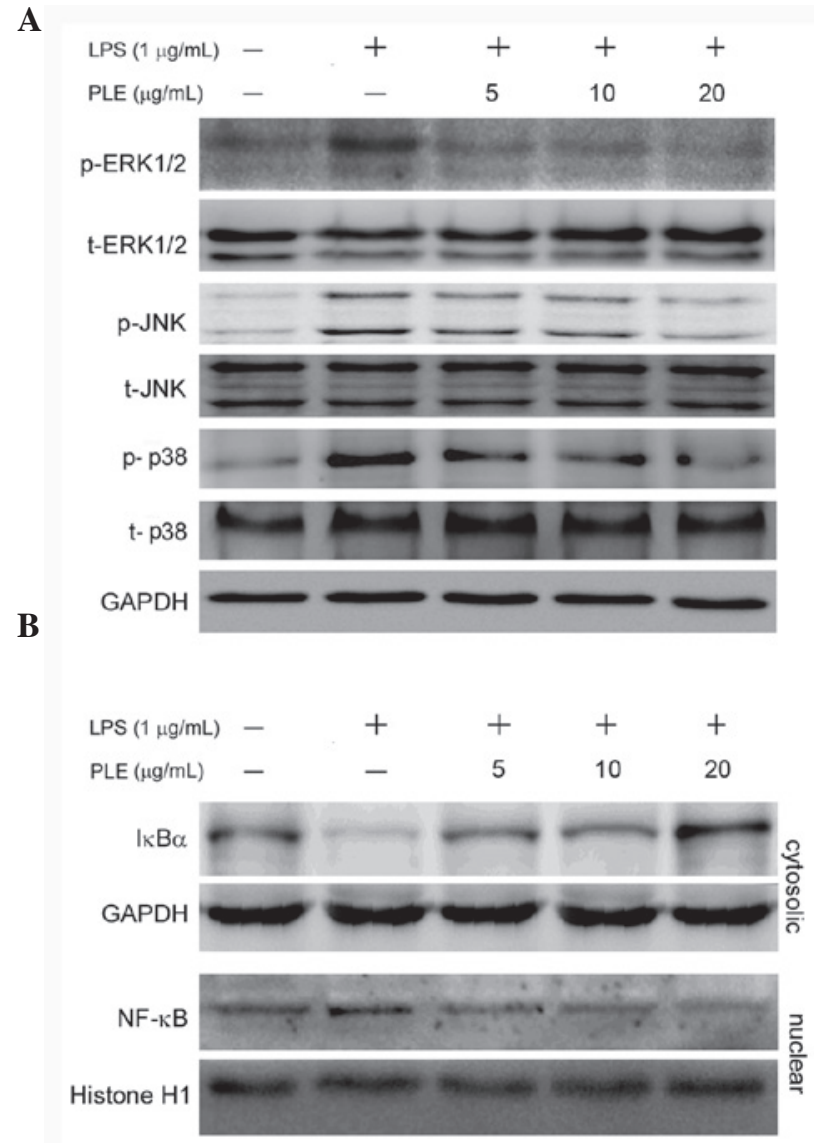

Figure 5. PLE reduces the phosphorylation of MAPKs and the nuclear translocation of NF- $\kappa \mathrm{B}$ in LPS-stimulated RAW264.7 cells. Cells were pre-incubated with the indicated concentrations of PLE in the DMEM culture medium for $4 \mathrm{~h}$, and were then stimulated with $1 \mu \mathrm{g} / \mathrm{ml}$ LPS for $1 \mathrm{~h}$. Following treatment, the cells were lysed and fractionated for protein extraction. (A) Phosphorylation and protein level of MAPKs and (B) protein level of cytosolic I $\kappa \mathrm{B} \alpha$ and nuclear $\mathrm{NF}-\kappa \mathrm{B}$ visualized by immunoblot assays using specific antibodies and a chemiluminescent substrate. The levels of GAPDH and histone $\mathrm{H} 1$ were used as controls. PLE, Perilla frutescens leaf extract; MAPKs, mitogen-activated protein kinases; NF- $\kappa B$, nuclear factor- $\kappa \mathrm{B}$; LPS, lipopolysaccharide; GAPDH, glyceraldehyde 3-phosphate dehydrogenase.

is known to be involved in LPS-induced production of pro-inflammatory cytokines (22-24). To investigate whether PLE regulates activation of MAPKs in response to LPS, the levels of phosphorylated ERK1/2, JNK and p38 were determined by immunoblotting in LPS-stimulated RAW264.7 cells. As shown in Fig. 5A, LPS alone considerably increased the phosphorylation of ERK1/2, JNK and p38 in RAW264.7 cells, and pretreatment with 5, 10 or $20 \mu \mathrm{g} / \mathrm{ml}$ PLE inhibited the LPS-induced phosphorylation of ERK1/2, JNK and p38 in a dose-dependent manner.

The transcription factor $\mathrm{NF}-\kappa \mathrm{B}$ plays a pivotal role in regulation of pro-inflammatory factors, and its nuclear translocation is associated with the expression of these factors (25). Thus, the effects of PLE on the cytosolic level of I $\mathrm{B} \alpha$ (that inhibits the nuclear translocation of $\mathrm{NF}-\kappa \mathrm{B}$ ) and the nuclear level of NF- $\kappa$ B were subsequently investigated in RAW264.7 cells exposed to LPS. As shown in Fig. 5B, exposure of RAW264.7 cells to LPS led to an important decrease in the cytosolic I $\kappa \mathrm{B} \alpha$ level, accompanied by the expected increase in the nuclear NF- $\kappa \mathrm{B}$ level. However, PLE pretreatment restored the LPS-decreased cytosolic $\mathrm{I} \kappa \mathrm{B} \alpha$ level and reduced the nuclear NF- $\kappa$ B level that had been increased by LPS treatment, in a dose-dependent manner. These findings revealed that PLE inhibits not only the degradation of $\mathrm{I} \kappa \mathrm{B} \alpha$, but also the nuclear translocation of $\mathrm{NF}-\kappa \mathrm{B}$.

\section{Discussion}

Macrophages were reported to be directly involved in the inflammatory response (26). One of the most important roles of macrophages is the production of various cytokines, reactive oxygen and nitrogen species, growth factors and chemokines as a response to signals such as bacterial LPS (27). Although the bioactive molecules produced by macrophages play important roles in inflammation, these molecules were also shown to exert undesirable effects to the cells (28). Therefore, modulation of these products may provide potential targets for the control of inflammatory diseases. IL-6 has various biological effects in a number of chronic endothelial dysfunctions such as modulation of hematopoiesis, proliferation and differentiation of lymphocytes, and induction of acute-phase reactions (29). IL-8 is generally recognized as a key intermediate regulator in acute inflammatory responses (30). TNF- $\alpha$ is an important mediator produced by activated macrophages and was shown to affect various biological processes, including the regulation and the production of other cytokines $(31,32)$. Our findings revealed that PLE inhibits the dendritic transformation of RAW264.7 cells and the expression of IL-6, IL-8 and TNF- $\alpha$ in LPS-stimulated RAW264.7 cells, suggesting that PLE may attenuate the LPS-induced activation of macrophages and the consequent production of inflammatory cytokines.

$\mathrm{NO}$ is an important mediator and regulator involved in inflammatory responses. In activated inflammatory cells, NO is produced at high levels by iNOS. COX-2 is regarded as a central mediator of inflammation, and regulation of $\mathrm{COX}-2$ was suggested to be useful in the development of a therapeutic target (33). Moreover, the enzymatic activity of COX-2 is directly affected by NO and iNOS $(34,35)$. Our results showed that PLE inhibits both $C O X-2$ and $i N O S$ expression, as well as NO production, which further supports that PLE can attenuate the inflammatory response.

LPS is known to activate several signaling kinases, including ERK1/2, MEK (36), JNK, AP-1 (22), p38 and other MAP kinase family members (37). Our findings show that PLE inhibits $i N O S$ expression and NO production in LPS-stimulated RAW264.7 cells, which may relate to the downregulation of $\mathrm{NF}-\kappa \mathrm{B}$ signaling components, including ERK1/2, JNK and p38. The inhibitory effect of PLE on NF- $\mathrm{B}, \mathrm{ERK} 1 / 2$ and JNK expression is crucial for the expression of iNOS.

In conclusion, the results from the present study indicate that PLE displays important anti-inflammatory activity in LPS-stimulated macrophage RAW264.7 cells, through inhibition of the expression of pro-inflammatory cytokines, inhibition of MAPK activation, and of NF- $\mathrm{NB}$ nuclear translocation in response to LPS.

\section{Acknowledgements}

This study was partly supported by grants from the National Science Council, Taiwan (nos. NSC99-2320-B-040-003-MY3 and NSC99-2632-B-040-001-MY3). 


\section{References}

1. Ueda $\mathrm{H}$ and Yamazaki M: Inhibition of tumor necrosis factor-alpha production by orally administering a Perilla leaf extract. Biosci Biotechnol Biochem 61: 1292-1295, 1997.

2. Makino T, Ono T, Muso E, Honda G and Sasayama S: Suppressive effects of Perilla frutescens on spontaneous IgA nephropathy in ddY mice. Nephron 83: 40-46, 1999.

3. Ueda $\mathrm{H}$ and Yamazaki M: Anti-inflammatory and anti-allergic actions by oral administration of a Perilla leaf extract in mice. Biosci Biotechnol Biochem 65: 1673-1675, 2001.

4. Shin TY, Kim SH, Kim SH, et al: Inhibitory effect of mast cell-mediated immediate-type allergic reactions in rats by Perilla frutescens. Immunopharmacol Immunotoxicol 22: 489-500, 2000.

5. Hortelano S, Zeini M and Bosca L: Nitric oxide and resolution of inflammation. Methods Enzymol 359: 459-465, 2002.

6. Paige JS and Jaffrey SR: Pharmacologic manipulation of nitric oxide signaling: targeting NOS dimerization and protein-protein interactions. Curr Top Med Chem 7: 97-114, 2007.

7. Gao YT, Panda SP, Roman LJ, Martasek P, Ishimura Y and Masters BS: Oxygen metabolism by neuronal nitric-oxide synthase. J Biol Chem 282: 7921-7929, 2007.

8. Breitbach K, Klocke S, Tschernig T, van Rooijen N, Baumann U and Steinmetz I: Role of inducible nitric oxide synthase and NADPH oxidase in early control of Burkholderia pseudomallei infection in mice. Infect Immun 74: 6300-6309, 2006.

9. Cunha IW, Lopes A, Falzoni R and Soares FA: Sarcomas often express constitutive nitric oxide synthases (NOS) but infrequently inducible NOS. Appl Immunohistochem Mol Morphol 14: 404-410, 2006.

10. Farley KS, Wang LF, Razavi HM, et al: Effects of macrophage inducible nitric oxide synthase in murine septic lung injury. Am J Physiol Lung Cell Mol Physiol 290: L1164-L1172, 2006.

11. Sacco RE, Waters WR, Rudolph KM and Drew ML: Comparative nitric oxide production by LPS-stimulated monocyte-derived macrophages from Ovis canadensis and Ovis aries. Comp Immunol Microbiol Infect Dis 29: 1-11, 2006.

12. Rahman A, Yatsuzuka R, Jiang S, Ueda Y and Kamei C: Involvement of cyclooxygenase-2 in allergic nasal inflammation in rats. Int Immunopharmacol 6: 1736-1742, 2006.

13. Geng Y, Zhang B and Lotz M: Protein tyrosine kinase activation is required for lipopolysaccharide induction of cytokines in human blood monocytes. J Immunol 151: 6692-6700, 1993.

14. Kim HS, Ye SK, Cho IH, et al: 8-hydroxydeoxyguanosine suppresses NO production and COX-2 activity via Rac1/STATs signaling in LPS-induced brain microglia. Free Radic Biol Med 41: 1392-1403, 2006

15. Park HJ, Kim IT, Won JH, et al: Anti-inflammatory activities of ent-16alphaH,17-hydroxy-kauran-19-oic acid isolated from the roots of Siegesbeckia pubescens are due to the inhibition of iNOS and COX-2 expression in RAW 264.7 macrophages via NF-kappaB inactivation. Eur J Pharmacol 558: 185-193, 2007.

16. Nakano H, Shindo M, Sakon S, et al: Differential regulation of IkappaB kinase alpha and beta by two upstream kinases, NF-kappaB-inducing kinase and mitogen-activated protein kinase/ERK kinase kinase-1. Proc Natl Acad Sci USA 95 3537-3542, 1998

17. Green LC, Wagner DA, Glogowski J, Skipper PL, Wishnok JS and Tannenbaum SR: Analysis of nitrate, nitrite, and [15N]nitrate in biological fluids. Anal Biochem 126: 131-138, 1982.

18. Saxena RK, Vallyathan V and Lewis DM: Evidence for lipopolysaccharide-induced differentiation of RAW264.7 murine macrophage cell line into dendritic like cells. J Biosci 28: 129-134, 2003.
19. Onuchic AC, Machado CM, Saito RF, Rios FJ, Jancar S and Chammas R: Expression of PAFR as part of a prosurvival response to chemotherapy: a novel target for combination therapy in melanoma. Mediators Inflamm 2012: 175408, 2012.

20. Chen H, Ma F, Hu X, Jin T, Xiong C and Teng X: Elevated COX2 expression and PGE2 production by downregulation of $\mathrm{RXR} \alpha$ in senescent macrophages. Biochem Biophys Res Commun 440: 157-162, 2013.

21. Adesso S, Popolo A, Bianco G, et al: The uremic toxin indoxyl sulphate enhances macrophage response to LPS. PloS One 8: e76778, 2013

22. Hambleton J, Weinstein SL, Lem L and DeFranco AL: Activation of c-Jun N-terminal kinase in bacterial lipopolysaccharide-stimulated macrophages. Proc Natl Acad Sci USA 93: 2774-2778, 1996.

23. An $\mathrm{H}, \mathrm{Yu} \mathrm{Y}$, Zhang M, et al: Involvement of ERK, p38 and NF-kappaB signal transduction in regulation of TLR2, TLR4 and TLR9 gene expression induced by lipopolysaccharide in mouse dendritic cells. Immunology 106: 38-45, 2002.

24. Wang W, Deng M, Liu X, Ai W, Tang Q and Hu J: TLR4 activation induces nontolerant inflammatory response in endothelial cells. Inflammation 34: 509-518, 2011.

25. Tak PP and Firestein GS: NF-kappaB: a key role in inflammatory diseases. J Clin Invest 107: 7-11, 2001.

26. Murakami A, Nishizawa T, Egawa K, et al: New class of linoleic acid metabolites biosynthesized by corn and rice lipoxygenases: suppression of proinflammatory mediator expression via attenuation of MAPK- and Akt-, but not PPARgamma-, dependent pathways in stimulated macrophages. Biochem Pharmacol 70: 1330-1342, 2005

27. Fujiwara $\mathrm{N}$ and Kobayashi K: Macrophages in inflammation. Curr Drug Targets Inflamm Allergy 4: 281-286, 2005.

28. Heumann D and Roger T: Initial responses to endotoxins and Gram-negative bacteria. Clin Chim Acta 323: 59-72, 2002.

29. Desai TR, Leeper NJ, Hynes KL and Gewertz BL: Interleukin-6 causes endothelial barrier dysfunction via the protein kinase $\mathrm{C}$ pathway. J Surg Res 104: 118-123, 2002.

30. Noda A, Kinoshita K, Sakurai A, Matsumoto T, Mugishima H and Tanjoh K: Hyperglycemia and lipopolysaccharide decrease depression effect of interleukin 8 production by hypothermia: an experimental study with endothelial cells. Intensive Care Med 34: 109-115, 2008.

31. Hume DA, Underhill DM, Sweet MJ, Ozinsky AO, Liew FY and Aderem A: Macrophages exposed continuously to lipopolysaccharide and other agonists that act via toll-like receptors exhibit a sustained and additive activation state. BMC Immunol 2: 11, 2001.

32. Aggarwal BB, Shishodia S, Ashikawa K and Bharti AC: The role of TNF and its family members in inflammation and cancer: lessons from gene deletion. Curr Drug Targets Inflamm Allergy 1: 327-341, 2002 .

33. Tsatsanis C, Androulidaki A, Venihaki M and Margioris AN: Signalling networks regulating cyclooxygenase-2. Int J Biochem Cell Biol 38: 1654-1661, 2006

34. Aggarwal BB, Shishodia S, Sandur SK, Pandey MK and Sethi G: Inflammation and cancer: how hot is the link? Biochem Pharmacol 72: 1605-1621, 2006.

35. Korhonen R, Lahti A, Kankaanranta $\mathrm{H}$ and Moilanen E: Nitric oxide production and signaling in inflammation. Curr Drug Targets Inflamm Allergy 4: 471-479, 2005.

36. Geppert TD, Whitehurst CE, Thompson P and Beutler B: Lipopolysaccharide signals activation of tumor necrosis factor biosynthesis through the ras/raf-1/MEK/MAPK pathway. Mol Med 1: 93-103, 1994.

37. Han J, Lee JD, Bibbs L and Ulevitch RJ: A MAP kinase targeted by endotoxin and hyperosmolarity in mammalian cells. Science 265: 808-811, 1994 